\title{
Analysis of two-component sensor proteins involved in the response to acid stimuli in Streptococcus pyogenes
}

\begin{abstract}
Correspondence
Tadao Hasegawa

tadaoh@med.nagoya-cu.ac.jp
\end{abstract}

Received 14 April 2011

Revised 18 August 2011

Accepted 24 August 2011

\author{
Mariko Ichikawa, Masaaki Minami, Masanori Isaka, Ichiro Tatsuno \\ and Tadao Hasegawa
}

\author{
Department of Bacteriology, Nagoya City University Graduate School of Medical Sciences, \\ 1 Kawasumi, Mizuho-cho, Mizuho-ku, Nagoya, Aichi 467-8601, Japan
}

\begin{abstract}
The virulence of Streptococcus pyogenes depends on proteins that are produced by this bacterium. The production of virulence proteins depends on environmental factors, and twocomponent regulatory systems are considered to be involved in sensing these factors. One of the environmental factors is acid stimuli. We established knockout strains in all speculated twocomponent regulatory sensor proteins of the M1 clinical strain of $S$. pyogenes and examined their relevance to acid stimuli. The parental strain and its derived knockout strains were cultured in a medium adjusted to $\mathrm{pH} 7.6$ or 6.0 , and their growth in broth was compared. The spy 1622 sensor knockout strain showed significant growth reduction compared with the parental strain in broth at $\mathrm{pH}$ 6.0, suggesting that the Spy1622 two-component sensor protein is involved in sensing acid stimuli. To further examine the role of the Spy1622 two-component sensor protein in virulence, blood bactericidal assays and mouse infection model experiments were performed. We found that the spy1622 knockout strain was less virulent than the parental strain, which suggests that the Spy1622 two-component sensor protein could play an important role in virulence.
\end{abstract}

\section{INTRODUCTION}

Streptococcus pyogenes is a Gram-positive bacterium that infects the upper respiratory tract, for example the tonsils and pharynx, and causes serious post-infectious diseases such as rheumatic fever and glomerulonephritis. Furthermore, $S$. pyogenes causes even more serious human diseases such as streptococcal toxic shock syndrome (STSS), whose mortality rate is considerable (Cone et al., 1987; Cunningham, 2000). Because of the worldwide prevalence of STSS, a number of studies have been undertaken to identify relevant virulence factors (Hauser et al., 1991; Reichardt et al., 1992). These factors include M protein, streptococcal inhibitor of complement, streptococcal pyrogenic toxins, haemolysins, and several DNases (Cunningham, 2000).

The production of virulence proteins depends on environmental factors such as $\mathrm{pH}$. Bacterial growth and the host environment, such as that in phagocytic cells, can cause local and temporal $\mathrm{pH}$ changes, and bacteria can subsequently sense the $\mathrm{pH}$ change as a signal to modify their growth mode. In addition, bacteria can modulate their

Abbreviations: HK, histidine kinase; STSS, streptococcal toxic shock syndrome; TCS, two-component regulatory system.

Supplementary methods and a supplementary table are available with the online version of this paper. gene expression in response to changes in $\mathrm{pH}$ (Loughman \& Caparon, 2006). Hence, $\mathrm{pH}$ is considered to play an important role in host colonization and infection by $S$. pyogenes.

The regulation of virulence protein expression in $S$. pyogenes is mainly controlled by stand-alone response regulators and two-component regulatory systems (TCSs). Stand-alone transcriptional regulators have no identified sensory domain (Kreikemeyer et al., 2003). The three characterized stand-alone regulators include Mga, Rgg and RofA-like family members (McIver et al., 1995; Beckert et al., 2001; Chaussee et al., 1999; Lyon et al., 1998; Molinari et al., 2001; Podbielski et al., 1999). A TCS consists of a sensor protein and a regulatory protein. Thirteen TCSs have been identified in the available $S$. pyogenes genome sequences from strains of serotypes M1, M2, M3, M4, M5, M6, M12, M18 and M28 (Sumby et al., 2005; Beres et al., 2006, 2002; Nakagawa et al., 2003; Holden et al., 2007; Banks et al., 2004; Smoot et al., 2002; Green et al., 2005; McShan et al., 2008). Some studies have analysed the involvement of TCSs in virulence; however, most experiments were carried out from the viewpoint of the regulators. In this study, we focused on sensor proteins of TCSs, established 13 types of sensor knockout mutants, and analysed their involvement in the acid response and their relevance to virulence using in vitro blood bactericidal assays and mouse infection model experiments. 


\section{METHODS}

S. pyogenes strains. The $S$. pyogenes strains used in this study were SF370 (Ferretti et al., 2001) and the 1529 clinical isolate from a Japanese patient with STSS. As far as CovS is concerned, comparison of the $\operatorname{cov} S$ sequence with that of SF370 indicated that the mutation in 1529 is the same as the one previously reported [994 $(A \rightarrow G)$, relative to the $\operatorname{cov} S$ start site, amino acid change $\mathrm{I} \rightarrow \mathrm{V}]$ (Sumby et al., 2005; Hasegawa et al., 2010b).

Culture conditions. An aliquot of bacterial stock solution stored frozen at $-80{ }^{\circ} \mathrm{C}$ was inoculated into $4 \mathrm{ml}$ Todd-Hewitt broth (Becton Dickinson) supplemented with $0.3 \%$ yeast extract (Becton Dickinson) (TH-YE) and cultured overnight at $37{ }^{\circ} \mathrm{C}$ without agitation. A $60-80 \mu \mathrm{l}$ volume of overnight culture was added to $4 \mathrm{ml}$ fresh TH-YE. The growth of bacteria was then monitored by a colorimeter (Asahi Science) via $\mathrm{OD}_{660}$. After confirmation that the growth of the bacteria was approximately the same, the bacteria were again freshly cultured in TH-YE broth, the $\mathrm{pH}$ of which was adjusted to 7.6 or 6.0 for $18 \mathrm{~h}$, and the growth was monitored. We checked the relationship between c.f.u. and optical density in all strains used, and confirmed that the cell numbers estimated by optical density were applicable to a comparison of the maximal growth of each strain. The mean estimated cell number observed from the optical density at $\mathrm{pH} 7.6$ of each strain was defined as $100 \%$ growth rate, and the growth rate at $\mathrm{pH} 6.0$ was calculated from the estimated maximal cell numbers at $\mathrm{pH} 6.0$ for each strain. The experiments were carried out at least in duplicate, and repeated at least three times independently.

Creation of the knockout strain. A nonpolar inactivated mutant was constructed through double-crossover allelic replacement in the chromosomes of S. pyogenes 1529 and SF370. The method was virtually the same as that by which the covS knockout strain was constructed previously (Sawai et al., 2007). The plasmids used for each sensor protein were constructed as described in Supplementary Methods and Supplementary Table S1. All PCRs were carried out with Pyrobest DNA polymerase or PrimeSTAR HS DNA polymerase (Takara), yielding blunt-ended DNA. The spc1, spc2 and spc3 DNA fragments containing aad9 (promoterless spectinomycin-resistance gene) were obtained from SmaI-digested fragments of pSL60-1, -2 and -3 , respectively (Lukomski et al., 2000). All plasmids for knockout were suicide vectors for $S$. pyogenes. For preparation of competent cells, strain 1529 or SF370 was harvested at early to midexponential phase $\left(\mathrm{OD}_{660} 0.4-0.5\right)$ and washed twice with $0.5 \mathrm{M}$ sucrose buffer. The constructed suicide vector was transformed into the strain by electroporation. Conditions of electroporation were $1.25 \mathrm{kV} \mathrm{mm}{ }^{-1}, 25 \mu \mathrm{F}$ capacitance and $200 \Omega$ resistance, using a Gene Pulser II (Bio-Rad). After incubation at $37{ }^{\circ} \mathrm{C}$ for $3 \mathrm{~h}$, competent cells were spread onto brain heart infusion-yeast extract (BHI-YE; Eiken Chemical) agar plates containing spectinomycin (final concentration $100 \mu \mathrm{g} \mathrm{ml}^{-1}$ ). Selected colonies on the plates were cultured. Cultured bacteria were washed once with saline, resuspended in $10 \mathrm{mM}$ Tris $/ 1 \mathrm{mM}$ EDTA, and boiled for $10 \mathrm{~min}$. Genomic DNA was obtained from the supernatant of boiled bacteria. Double-crossover replacement with genomic DNA was analysed by PCR. Successful double-crossover replacement was further confirmed by DNA sequencing.

To construct a plasmid for spy1622 complementation, the DNA fragment containing spy1622 was amplified with oligonucleotide primers 1622-n4Nhe and 1622-c1 (see Supplementary Table S1) with PrimeSTAR HS DNA polymerase. The fragment digested with RsaI, which contained all of the coding region of Spy1622, was ligated into the SmaI site of the pLZ12-Km2 plasmid (Okada et al., 1998). The protocol for transformation was the same as that described above, except that the competent cells were spread onto BHI-YE agar plates containing spectinomycin and kanamycin (final concentrations 100 and $200 \mu \mathrm{g} \mathrm{ml}^{-1}$, respectively).

Lancefield bactericidal assay. Lancefield bactericidal assays (Loughman \& Caparon, 2006; Lancefield, 1957) were performed as described previously (Hasegawa et al., 2010a). In brief, approximately 1000 c.f.u. of cells from the late-exponential phase of growth were added to $1 \mathrm{ml}$ heparinized human whole blood, which had been pretreated for 15 min with or without $10 \mu \mathrm{M}$ cytochalasin D (Wako Pure Chemical Industries) (von Delwig et al., 2002) to clarify the mechanism of neutrophil killing, and were rotated at $37{ }^{\circ} \mathrm{C}$. In addition, we carried out another experiment in which the strains were incubated in human serum inactivated at $65{ }^{\circ} \mathrm{C}$ for $30 \mathrm{~min}$ before the bactericidal assay. Diluted samples of blood were plated on BHI-YE agar plates at the indicated time points to determine the number of c.f.u. The growth rate was calculated from the number of c.f.u. at a given time point divided by the initial c.f.u. at time zero. The growth rate data at each time point were tested for significance using analysis of variance (ANOVA; Tukey's method). Data are the mean growth ratios from three independent experiments. Error bars depict SEM.

Mouse model of invasive skin and soft tissue infection. The procedure used was the same as that described previously (Hasegawa et al., 2010a; Tatsuno et al., 2010). In brief, parental, mutant and complemented cells of $S$. pyogenes were harvested after $16 \mathrm{~h}$ of growth on BHI-YE agar plates. The cells were harvested with appropriate antibiotics into $1 \mathrm{ml}$ PBS $(\times 1, \mathrm{pH} 7.4)$ and then centrifuged at $2000 \mathrm{~g}$ for $2 \mathrm{~min}$. The pellets were diluted to $1 \times 10^{8}$ c.f.u. in $100 \mu \mathrm{l}$ PBS and then injected (with a 25-gauge needle) under the skin surface of 3 week-old female Slc:ICR mice after they had been anaesthetized by ketamine-xylazine injection. Ten mice of each strain were used for this experiment. The number of c.f.u. injected was verified for each experiment by plating bacteria on BHI-YE agar plates and then counting c.f.u. The mice were observed daily for lesion and necrosis formation. Survival data were assessed by Kaplan-Meier survival analysis and tested for significance by the logrank test. Lesion sizes (length $\times$ width) were measured, with the length determined as the longest dimension of the lesion at day 3 or at the death time point. The data for lesion size were tested for significance using ANOVA (Tukey's method). All animal procedures were approved by the Institutional Animal Care and Use Committee at Nagoya City University.

\section{RESULTS}

\section{Analysis of the effect of sensor proteins on growth of the bacteria cultured at pH 7.6 or $\mathbf{6 . 0}$}

To test the effect of sensor proteins of $S$. pyogenes on growth in acidic $\mathrm{pH}$ conditions, we first attempted to establish knockout mutants in all 13 speculated sensor proteins. We successfully established all sensor protein knockout strains derived from strain 1529. We cultured the parental strain and derived knockout strains in medium whose $\mathrm{pH}$ was adjusted to 7.6 or 6.0 , and the decreases in growth rates were compared. As shown in Fig. 1, the growth of all strains was inhibited at $\mathrm{pH} 6.0$ compared with that at $\mathrm{pH}$ 7.6. However, the decrease in the growth rate of spy1622 $(60.8 \%)$ was significantly greater than that of the parental strain 1529 (50.6\%) (two-way repeated measures ANOVA, $P=0.0024$ ). There was no statistically significant difference in the extent of decrease in the other two-component sensor knockout strains. However, in the 


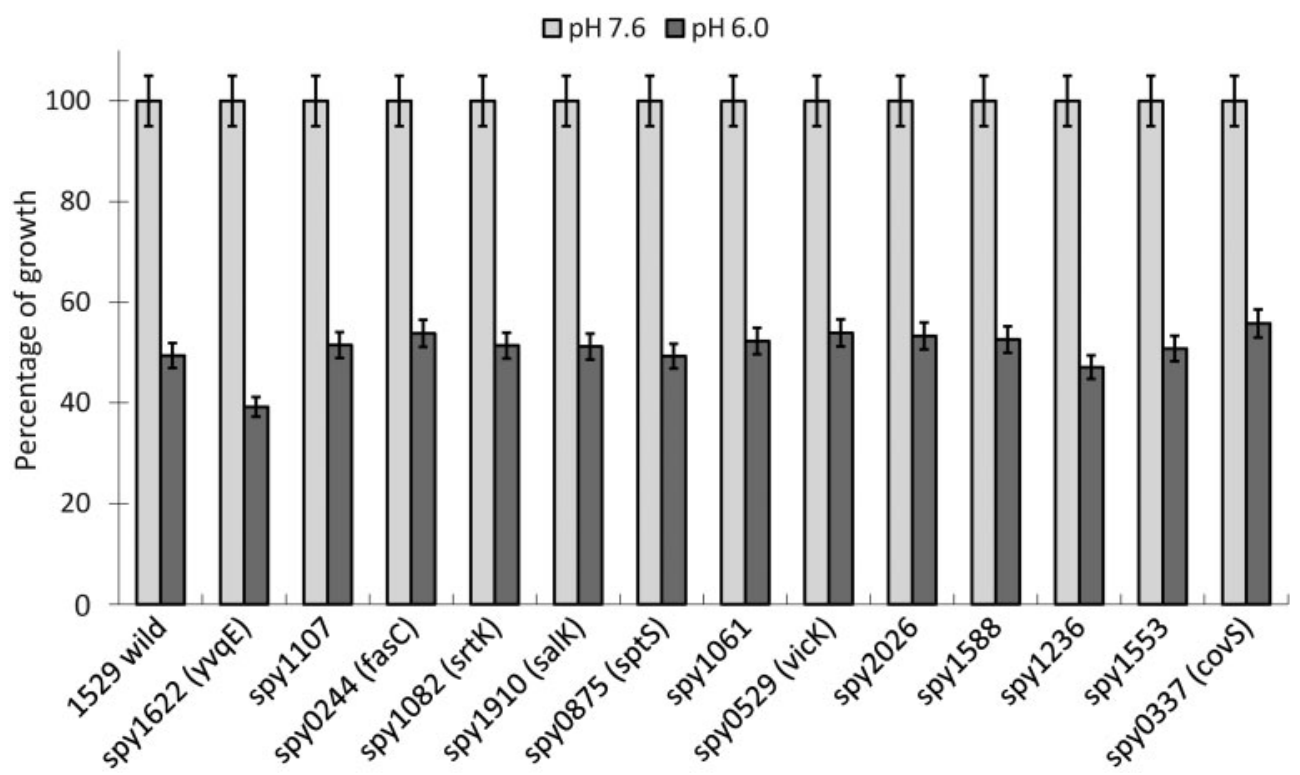

Fig. 1. Analysis of the growth of sensor knockout strains cultured under acidic conditions. Wild-type strain 1529 and its derived sensor knockout strains were cultured in broth at $\mathrm{pH} 7.6$ or 6.0 , and growth was assessed after 18 h. The percentage of growth of each strain cultured at $\mathrm{pH} 7.6$ was defined as $100 \%$ and the percentage of growth at $\mathrm{pH} 6.0$ was calculated from this.

case of the spy0529 knockout, the decrease in growth rate $(46.1 \%)$ was less than that of the wild-type strain 1529 $(50.6 \%)(P=0.0084)$.

In this study, we focused on Spy1622, because this protein seems to play a role in acid resistance though not in acid tolerance. To rule out effects related to the specificity of the strain, we established a spy 1622 knockout strain from strain SF370. Complemented strains derived from knockout strains SF370 and 1529 were also established, and the same experiments were performed. As shown in Fig. 2(a), a significant decrease in the growth of the SF370 spy1622 knockout after $18 \mathrm{~h}$ incubation could be confirmed (56.8\% compared with $41.0 \%$ for the SF370 wild-type) $(P<0.0001)$. A smaller decrease in growth in the complemented strain than in the knockout strain was confirmed (SF370 complemented strain $48.3 \%)(P=0.0011)$ (Fig. 2a); however, in the case of strain 1529, we detected only a partial effect of complementation (knockout $56.7 \%$, complemented $54.4 \%$ ) (Fig. 2b). In addition, the speed of growth of the wild and knockout strains was similar, and lower growth of the knockout was also obtained after 6 and $24 \mathrm{~h}$ incubation (data not shown). Thus these results suggest that the lower growth levels of the spy1622 mutants were not due to slower overall growth, and that the effect is not strain-dependent but Spy1622-dependent.

\section{In vitro blood bactericidal assay}

Acid conditions play an important role in the destruction of bacteria by phagocytosis. To determine whether Spy1622 affected the bactericidal function of human leukocytes, we performed bactericidal assays with human blood. For this purpose, we used the parental strain 1529, its derived spy1622 knockout mutant strain, and a spy1622complemented strain. Fig. 3(a) shows that the growth rate ( $y$ axis) of the spy1622 knockout was less than that of the parental strain after $30,60,90$ and $120 \mathrm{~min}(P<0.05$ at $120 \mathrm{~min}$ ). The growth rate of the complemented strain was similar to that of the parental strain. We also performed a bactericidal assay in which neutrophil phagocytosis was inhibited by cytochalasin $\mathrm{D}$ to see whether the killing was extracellular or intracellular. As shown in Fig. $3(\mathrm{~b})$, all the growth rates were almost the same, suggesting that the neutrophil killing was intracellular. Another experiment in which the strains were incubated in plasma was carried out, but there was no significant survival difference among the strains (data not shown). These results imply that the spy1622 knockout strain is destroyed intracellularly more efficiently by human blood cells than the parental strain.

\section{Analysis of virulence in a mouse infection model}

To examine virulence, we performed mouse infection model experiments using the parental M1 serotype 1529 and knockout strains. As shown in Fig. 4(a), mice were injected subcutaneously with the parental, spy1622 knockout and complemented strains, and it was found that the mice injected with the knockout strain survived longer than those injected with the parental strain $(P=0.0104)$. The complemented strain slightly rescued survival, although there was no significant difference. The local skin lesions were smaller in mice injected with the 

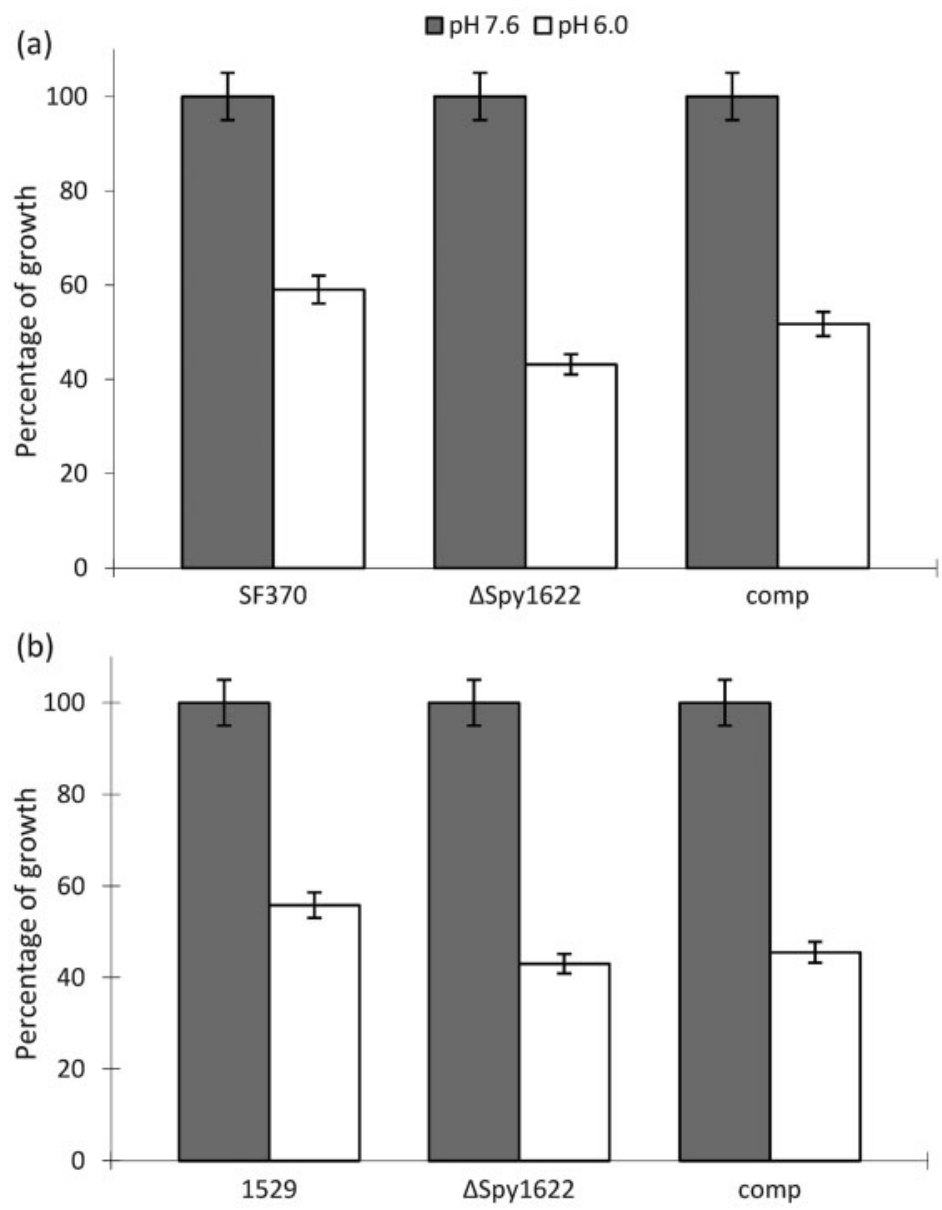

Fig. 2. Analysis of the growth of wild-type, spy1622 knockout and complemented strains cultured under acidic conditions. Wild-type strains SF370 (a) and strain 1529 (b), and their derived spy1622 knockout and complemented (comp) strains, were cultured in broth at $\mathrm{pH} 7.6$ or 6.0 , and growth was assessed after $18 \mathrm{~h}$. The percentage of growth of each strain cultured at $\mathrm{pH} 7.6$ was defined as $100 \%$ and the percentage of growth at $\mathrm{pH} 6.0$ was calculated from this.

knockout strain $(P<0.01)$. Furthermore, the local skin lesions caused by the complemented strain were significantly larger than those of the knockout strain $(P<0.01)$ (Fig. 4b). These results suggest that the Spy1622 sensor protein plays an important role in virulence in mouse infection model experiments.

\section{DISCUSSION}

S. pyogenes produces many types of protein, including virulence proteins, in response to environmental stresses. By using 2D gel electrophoresis (2-DE) and mass analysis, we have so far identified several DNases (Hasegawa et al., 2002a, b, 2010a). We have also studied the influence of various culture conditions on the production of these exoproteins (Nakamura et al., 2004; Tanaka et al., 2005; Sawai et al., 2007; Minami et al., 2010). One of the mechanisms by which protein expression is controlled depends on TCSs; in particular, sensor proteins sense alterations on the outer surface of cells. In this study, we examined whether any sensor proteins (histidine kinases; HKs) of TCSs could play a role in response to acid stimuli, because acid stimuli are considered to play an important role in virulence. One of the defence mechanisms of the host against bacteria, including S. pyogenes, is phagocytosis. Phagosome maturation can be viewed as the end of a phagocytic process during which internalized bacteria are efficiently degraded. Acidification is essential during phagosome maturation. If the phagosome does not reach a sufficiently low $\mathrm{pH}$, the lytic activity of a variety of degradative enzymes is impaired and the generation of hydrogen peroxide is not promoted, and thus the process of degradation of phagocytosed bacteria cannot begin (Kinchen \& Ravichandran, 2008; Huynh \& Grinstein, 2007). Mycobacterium tuberculosis has been well studied in this regard. Acid resistance strategies in the phagosome that favour survival have been demonstrated (Ehrt \& Schnappinger, 2009; Vandal et al., 2009). Other than the involvement of phagocytosis, a study using $S$. pyogenes has shown that acidification resulting from fermentative sugar metabolism drives pilus expression, and the ability to form biofilms on abiotic surfaces and microcolonies on epithelial cells (Manetti et al., 2010). Thus, the acid response is considered to be closely related to the virulence of $S$. pyogenes.

Although Sitkiewicz et al. (2010) have carried out transcriptome analysis to study the response of $S$. pyogenes to amniotic fluid and have shown that spy1622 expression 
(a)

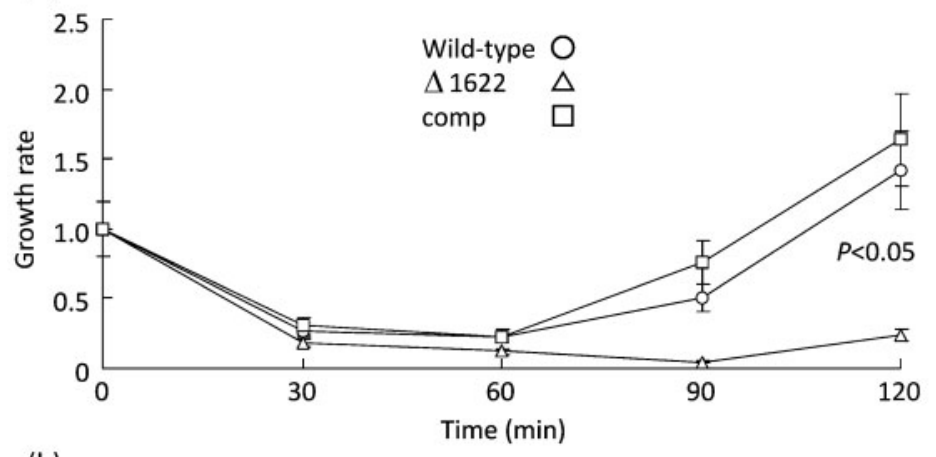

(b)

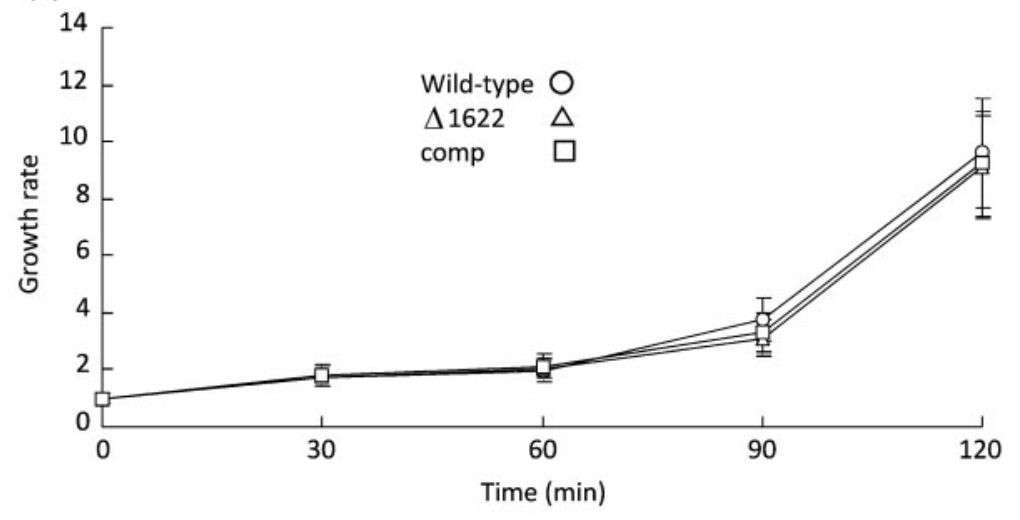

Fig. 3. In vitro blood bactericidal assay. The wild-type strain 1529, a spy1622 knockout strain or a spy1622-complemented (comp) strain $(100 \mu \mathrm{l})$ was mixed with human blood $(200 \mu l)$ without $(a)$ or with (b) cytochalasin D, and was incubated at $37{ }^{\circ} \mathrm{C}$ for $30 \mathrm{~min}$ to yield a final concentration of $10^{5}$ c.f.u. $\mathrm{ml}^{-1}$. Aliquots were removed and plated on $\mathrm{BHI}-\mathrm{YE}$ agar plates for quantification. The growth rate equals the number of c.f.u. at a given time point divided by the initial c.f.u. at time zero. Data represent mean values from three independent assays.

is increased, the functions of Spy1622 and what Spy1622 senses are not completely known. According to the DNA database, spy1622 of S. pyogenes is designated $y v q E$. The $y v q E$ gene is found in other bacteria such as Bacillus subtilis (Kunst et al., 1997; Fabret et al., 1999), Enterococcus faecalis (Hancock \& Perego, 2002), Streptococcus dysgalactiae subsp. equisimilis and Streptococcus equi subsp. zooepidemicus. Mascher and co-workers renamed YvqEC as LiaRS (Mascher et al., 2004), and showed that LiaRS is one of the three TCSs that respond to cell envelope stresses induced by cell wall-specific antibiotics such as bacitracin (Mascher et al., 2003). Thus, Spy1622 is considered to be a homologue of the YvqE or LiaS sensor protein. LiaS-like intramembrane-sensing HKs are found in many bacteria (Mascher, 2006). A LiaRS homologue, the VraSR system of Staphylococcus aureus, has also been reported to contribute to antibiotic resistance in clinical isolates of Staph. aureus (Boyle-Vavra et al., 2006; Gardete et al., 2006; Kuroda et al., $2003,2000)$. Other than the cell wall stress responses, LiaS (formerly designated HK11) has been found to play a role in acid resistance; it may act as a pH sensor (Li et al., 2002) and regulate virulence factor expression in Streptococcus mutans (Chong et al., 2008). In addition, LiaS of S. mutans has also been shown to be involved in tolerance to various inhibitors that target protein synthesis, DNA synthesis and cell wall biosynthesis (Zhang \& Biswas, 2009). The results of studies on S. mutans are in accordance with our data and may support our results, thus indicating that Spy1622 is involved in the response to acid stimuli.
Dalton \& Scott (2004) have reported that the growth of a CovS knockout mutant strain derived from M6 serotype strain JRS4 is impaired at low $\mathrm{pH}$. In addition, Santi et al. (2009) have reported that a CovRS homologue in Streptococcus agalactiae is involved in the $\mathrm{pH}$-dependent regulation of gene expression. In this study, we did not identify a significant role for CovS but showed that Spy1622 could be involved in the response to acid stimuli. The reason why we could not identify clear growth differences between wild-type and covS knockout strains in our study remains unknown. Treviño et al. (2009) have stated that they also observed no difference in growth for several wild-type and $\operatorname{cov} S$ mutant pairs grown under general stress conditions such as low $\mathrm{pH}$. One possibility is the existence of differences between strains, a second possibility is that strain 1529 already has one amino acid mutation in CovS, and a third possibility is the existence of differences in the methods used to assess bacterial growth. We cannot completely rule out the possibility that CovS is involved in acid sensing in our experimental design. We believe further experiments are necessary to confirm the involvement of CovS.

In addition, our comprehensive sensor knockout analysis showed that Spy0529 (VicK) may also be involved in the response to acid stimuli. The involvement of the VicK sensor kinase of $S$. mutans in both acidogenicity and aciduricity has been observed, while an acid tolerance response assay has revealed that loss of the VicK sensor kinase significantly enhances the survival of $S$. mutans 

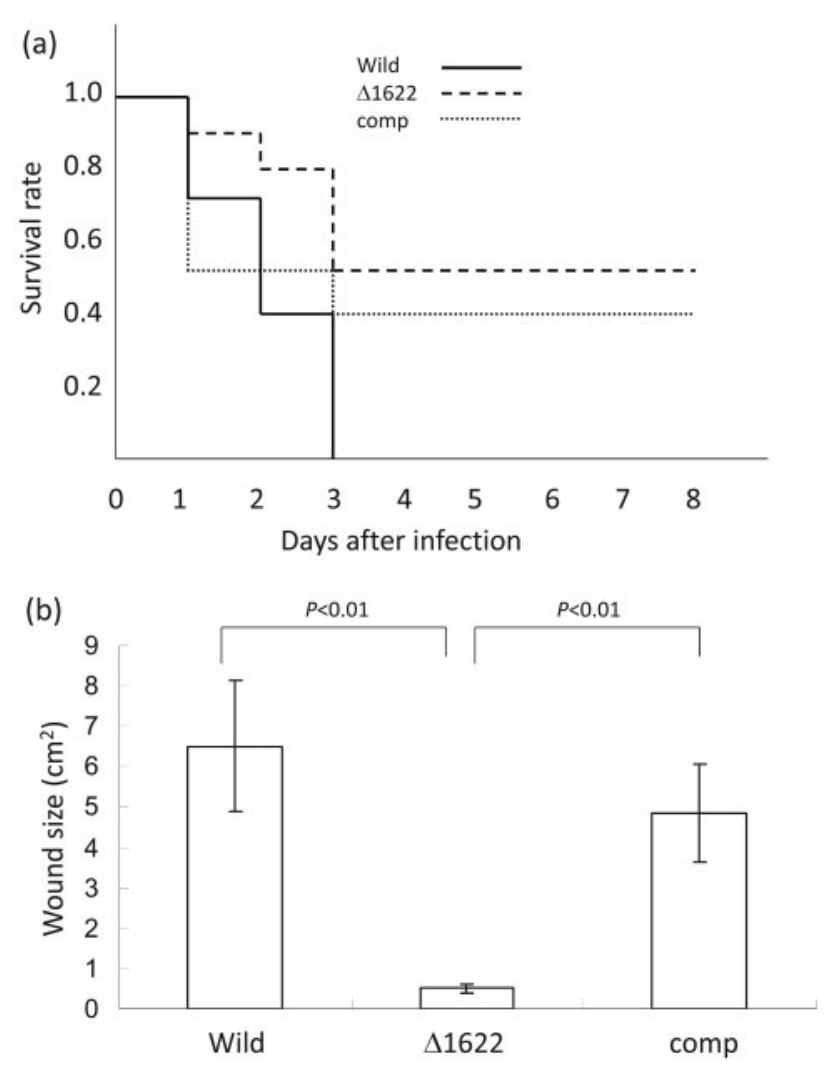

Fig. 4. Mouse infection model experiments. (a) Survival after subcutaneous injection with wild-type strain 1529, the spy1622 knockout mutant and the complemented strain (comp). Slc:ICR mice were injected subcutaneously with parental strain 1529, knockout and complemented strains. Mice were observed daily. Survival data were assessed by Kaplan-Meier survival analysis and tested for significance by the logrank test. (b) Analysis of lesions after subcutaneous challenge. Mice were observed daily for lesion and necrosis formation. Lesion size (length $\times$ width) was measured, with the length determined as the longest dimension of the lesion at day 3 or at the death time point. The data for lesion size were tested for significance using ANOVA (Tukey's method).

(Senadheera et al., 2009). Walkmycin C (WKM C), an HK inhibitor isolated during the screening of inhibitors of WalK HK in B. subtilis, inhibits the in vitro autophosphorylation activity of the three S. mutans HKs, i.e. VicK, $\mathrm{CiaH}$ and LiaS. When cells are pretreated with WKM C, an increase in acid sensitivity is observed (Eguchi et al., 2011). Thus, VicK of $S$. pyogenes could also be involved in the response to acid stimuli.

In conclusion, our results suggest that Spy1622 is involved in the response to acid stimuli, and thus plays an important role in the virulence of $S$. pyogenes. Further studies to examine the interaction of Spy1622 with other twocomponent sensor proteins, including VicK and CovS, will be necessary to reveal the details of the response to acid and its relationship with the virulence of $S$. pyogenes, and to assess whether these proteins could be targets in the control of infectious streptococcal diseases.

\section{ACKNOWLEDGEMENTS}

This study was supported by the Ministry of Education, Science and Culture of the Japanese government (grant no. 21590485) and a grant from Ohyama Health Foundation Inc. We thank Dr S. Lukomski, West Virginia University, for providing pFW12, and the pSL60-1, -2 and -3 plasmids.

\section{REFERENCES}

Banks, D. J., Porcella, S. F., Barbian, K. D., Beres, S. B., Philips, L. E., Voyich, J. M., DeLeo, F. R., Martin, J. M., Somerville, G. A. \& Musser, J. M. (2004). Progress toward characterization of the group A Streptococcus metagenome: complete genome sequence of a macrolide-resistant serotype M6 strain. J Infect Dis 190, 727-738.

Beckert, S., Kreikemeyer, B. \& Podbielski, A. (2001). Group A streptococcal rofA gene is involved in the control of several virulence genes and eukaryotic cell attachment and internalization. Infect Immun 69, 534-537.

Beres, S. B., Sylva, G. L., Barbian, K. D., Lei, B., Hoff, J. S., Mammarella, N. D., Liu, M. Y., Smoot, J. C., Porcella, S. F. \& other authors (2002). Genome sequence of a serotype M3 strain of group A Streptococcus: phage-encoded toxins, the high-virulence phenotype, and clone emergence. Proc Natl Acad Sci U S A 99, 10078-10083.

Beres, S. B., Richter, E. W., Nagiec, M. J., Sumby, P., Porcella, S. F., DeLeo, F. R. \& Musser, J. M. (2006). Molecular genetic anatomy of inter- and intraserotype variation in the human bacterial pathogen group A Streptococcus. Proc Natl Acad Sci U S A 103, 7059-7064.

Boyle-Vavra, S., Yin, S. \& Daum, R. S. (2006). The VraS/VraR twocomponent regulatory system required for oxacillin resistance in community-acquired methicillin-resistant Staphylococcus aureus. FEMS Microbiol Lett 262, 163-171.

Chaussee, M. S., Ajdic, D. \& Ferretti, J. J. (1999). The rgg gene of Streptococcus pyogenes NZ131 positively influences extracellular SPE B production. Infect Immun 67, 1715-1722.

Chong, P., Drake, L. \& Biswas, I. (2008). LiaS regulates virulence factor expression in Streptococcus mutans. Infect Immun 76, 30933099.

Cone, L. A., Woodard, D. R., Schlievert, P. M. \& Tomory, G. S. (1987). Clinical and bacteriologic observations of a toxic shock-like syndrome due to Streptococcus pyogenes. N Engl J Med 317, 146-149.

Cunningham, M. W. (2000). Pathogenesis of group A streptococcal infections. Clin Microbiol Rev 13, 470-511.

Dalton, T. L. \& Scott, J. R. (2004). CovS inactivates CovR and is required for growth under conditions of general stress in Streptococcus pyogenes. J Bacteriol 186, 3928-3937.

Eguchi, Y., Kubo, N., Matsunaga, H., Igarashi, M. \& Utsumi, R. (2011). Development of an antivirulence drug against Streptococcus mutans: repression of biofilm formation, acid tolerance, and competence by a histidine kinase inhibitor, walkmycin C. Antimicrob Agents Chemother 55, 1475-1484.

Ehrt, S. \& Schnappinger, D. (2009). Mycobacterial survival strategies in the phagosome: defence against host stresses. Cell Microbiol 11, 1170-1178.

Fabret, C., Feher, V. A. \& Hoch, J. A. (1999). Two-component signal transduction in Bacillus subtilis: how one organism sees its world. J Bacteriol 181, 1975-1983. 
Ferretti, J. J., McShan, W. M., Ajdic, D., Savic, D. J., Savic, G., Lyon, K., Primeaux, C., Sezate, S., Suvorov, A. N. \& other authors (2001). Complete genome sequence of an M1 strain of Streptococcus pyogenes. Proc Natl Acad Sci U S A 98, 4658-4663.

Gardete, S., Wu, S. W., Gill, S. \& Tomasz, A. (2006). Role of VraSR in antibiotic resistance and antibiotic-induced stress response in Staphylococcus aureus. Antimicrob Agents Chemother 50, 3424-3434.

Green, N. M., Zhang, S., Porcella, S. F., Nagiec, M. J., Barbian, K. D., Beres, S. B., LeFebvre, R. B. \& Musser, J. M. (2005). Genome sequence of a serotype M28 strain of group A Streptococcus: potential new insights into puerperal sepsis and bacterial disease specificity. J Infect Dis 192, 760-770.

Hancock, L. \& Perego, M. (2002). Two-component signal transduction in Enterococcus faecalis. J Bacteriol 184, 5819-5825.

Hasegawa, T., Torii, K., Hashikawa, S., linuma, Y. \& Ohta, M. (2002a). Cloning and characterization of two novel DNases from Streptococcus pyogenes. Arch Microbiol 177, 451-456.

Hasegawa, T., Torii, K., Hashikawa, S., linuma, Y. \& Ohta, M. (2002b). Cloning and characterization of the deoxyribonuclease $s d \alpha$ gene from Streptococcus pyogenes. Curr Microbiol 45, 13-17.

Hasegawa, T., Minami, M., Okamoto, A., Tatsuno, I., Isaka, M. \& Ohta, M. (2010a). Characterization of a virulence-associated and cellwall-located DNase of Streptococcus pyogenes. Microbiology 156, 184190.

Hasegawa, T., Okamoto, A., Kamimura, T., Tatsuno, I., Hashikawa, S. N., Yabutani, M., Matsumoto, M., Yamada, K., Isaka, M. \& other authors (2010b). Detection of invasive protein profile of Streptococcus pyogenes M1 isolates from pharyngitis patients. APMIS 118, 167-178.

Hauser, A. R., Stevens, D. L., Kaplan, E. L. \& Schlievert, P. M. (1991). Molecular analysis of pyrogenic exotoxins from Streptococcus pyogenes isolates associated with toxic shock-like syndrome. J Clin Microbio 29, 1562-1567.

Holden, M. T., Scott, A., Cherevach, I., Chillingworth, T., Churcher, C., Cronin, A., Dowd, L., Feltwell, T., Hamlin, N. \& other authors (2007). Complete genome of acute rheumatic fever-associated serotype M5 Streptococcus pyogenes strain Manfredo. J Bacteriol 189, 1473-1477.

Huynh, K. K. \& Grinstein, S. (2007). Regulation of vacuolar pH and its modulation by some microbial species. Microbiol Mol Biol Rev 71, $452-462$.

Kinchen, J. M. \& Ravichandran, K. S. (2008). Phagosome maturation: going through the acid test. Nat Rev Mol Cell Biol 9, 781-795.

Kreikemeyer, B., Mclver, K. S. \& Podbielski, A. (2003). Virulence factor regulation and regulatory networks in Streptococcus pyogenes and their impact on pathogen-host interactions. Trends Microbiol 11, 224-232.

Kunst, F., Ogasawara, N., Moszer, I., Albertini, A. M., Alloni, G., Azevedo, V., Bertero, M. G., Bessières, P., Bolotin, A. \& other authors (1997). The complete genome sequence of the Gram-positive bacterium Bacillus subtilis. Nature 390, 249-256.

Kuroda, M., Kuwahara-Arai, K. \& Hiramatsu, K. (2000). Identification of the up- and down-regulated genes in vancomycin-resistant Staphylococcus aureus strains Mu3 and Mu50 by cDNA differential hybridization method. Biochem Biophys Res Commun 269, 485-490.

Kuroda, M., Kuroda, H., Oshima, T., Takeuchi, F., Mori, H. \& Hiramatsu, K. (2003). Two-component system VraSR positively modulates the regulation of cell-wall biosynthesis pathway in Staphylococcus aureus. Mol Microbiol 49, 807-821.

Lancefield, R. C. (1957). Differentiation of group A streptococci with a common $\mathrm{R}$ antigen into three serological types, with special reference to the bactericidal test. J Exp Med 106, 525-544.
Li, Y. H., Lau, P. C., Tang, N., Svensäter, G., Ellen, R. P. \& Cvitkovitch, D. G. (2002). Novel two-component regulatory system involved in biofilm formation and acid resistance in Streptococcus mutans. J Bacteriol 184, 6333-6342.

Loughman, J. A. \& Caparon, M. (2006). Regulation of SpeB in Streptococcus pyogenes by $\mathrm{pH}$ and $\mathrm{NaCl}$ : a model for in vivo gene expression. J Bacteriol 188, 399-408.

Lukomski, S., Hoe, N. P., Abdi, I., Rurangirwa, J., Kordari, P., Liu, M., Dou, S. J., Adams, G. G. \& Musser, J. M. (2000). Nonpolar inactivation of the hypervariable streptococcal inhibitor of complement gene $(s i c)$ in serotype M1 Streptococcus pyogenes significantly decreases mouse mucosal colonization. Infect Immun 68, 535-542.

Lyon, W. R., Gibson, C. M. \& Caparon, M. G. (1998). A role for trigger factor and an rgg-like regulator in the transcription, secretion and processing of the cysteine proteinase of Streptococcus pyogenes. EMBO J 17, 6263-6275.

Manetti, A. G., Köller, T., Becherelli, M., Buccato, S., Kreikemeyer, B., Podbielski, A., Grandi, G. \& Margarit, I. (2010). Environmental acidification drives $S$. pyogenes pilus expression and microcolony formation on epithelial cells in a FCT-dependent manner. PLoS ONE 5, e13864.

Mascher, T. (2006). Intramembrane-sensing histidine kinases: a new family of cell envelope stress sensors in Firmicutes bacteria. FEMS Microbiol Lett 264, 133-144.

Mascher, T., Margulis, N. G., Wang, T., Ye, R. W. \& Helmann, J. D. (2003). Cell wall stress responses in Bacillus subtilis: the regulatory network of the bacitracin stimulon. Mol Microbiol 50, 1591-1604.

Mascher, T., Zimmer, S. L., Smith, T. A. \& Helmann, J. D. (2004). Antibiotic-inducible promoter regulated by the cell envelope stresssensing two-component system LiaRS of Bacillus subtilis. Antimicrob Agents Chemother 48, 2888-2896.

Mclver, K. S., Heath, A. S., Green, B. D. \& Scott, J. R. (1995). Specific binding of the activator Mga to promoter sequences of the emm and $s c p A$ genes in the group A streptococcus. J Bacteriol 177, 6619-6624.

McShan, W. M., Ferretti, J. J., Karasawa, T., Suvorov, A. N., Lin, S., Qin, B., Jia, H., Kenton, S., Najar, F. \& other authors (2008). Genome sequence of a nephritogenic and highly transformable M49 strain of Streptococcus pyogenes. J Bacteriol 190, 7773-7785.

Minami, M., Kamimura, T., Isaka, M., Tatsuno, I., Ohta, M. \& Hasegawa, T. (2010). Clindamycin-induced CovS-mediated regulation of the production of virulent exoproteins streptolysin $\mathrm{O}$, NAD glycohydrolase, and streptokinase in Streptococcus pyogenes. Antimicrob Agents Chemother 54, 98-102.

Molinari, G., Rohde, M., Talay, S. R., Chhatwal, G. S., Beckert, S. \& Podbielski, A. (2001). The role played by the group A streptococcal negative regulator Nra on bacterial interactions with epithelial cells. Mol Microbiol 40, 99-114.

Nakagawa, I., Kurokawa, K., Yamashita, A., Nakata, M., Tomiyasu, Y., Okahashi, N., Kawabata, S., Yamazaki, K., Shiba, T. \& other authors (2003). Genome sequence of an M3 strain of Streptococcus pyogenes reveals a large-scale genomic rearrangement in invasive strains and new insights into phage evolution. Genome Res 13 (6A, ), 1042-1055.

Nakamura, T., Hasegawa, T., Torii, K., Hasegawa, Y., Shimokata, K. \& Ohta, M. (2004). Two-dimensional gel electrophoresis analysis of the abundance of virulent exoproteins of group A streptococcus caused by environmental changes. Arch Microbiol 181, 74-81.

Okada, N., Tatsuno, I., Hanski, E., Caparon, M. \& Sasakawa, C. (1998). Streptococcus pyogenes protein F promotes invasion of HeLa cells. Microbiology 144, 3079-3086.

Podbielski, A., Woischnik, M., Leonard, B. A. \& Schmidt, K. H. (1999). Characterization of $n r a$, a global negative regulator gene in group A streptococci. Mol Microbiol 31, 1051-1064. 
Reichardt, W., Müller-Alouf, H., Alouf, J. E. \& Köhler, W. (1992). Erythrogenic toxins A, B and C: occurrence of the genes and exotoxin formation from clinical Streptococcus pyogenes strains associated with streptococcal toxic shock-like syndrome. FEMS Microbiol Lett 79, 313-322.

Santi, I., Grifantini, R., Jiang, S. M., Brettoni, C., Grandi, G., Wessels, M. R. \& Soriani, M. (2009). CsrRS regulates group B Streptococcus virulence gene expression in response to environmental $\mathrm{pH}$ : a new perspective on vaccine development. J Bacteriol 191, 5387-5397.

Sawai, J., Hasegawa, T., Kamimura, T., Okamoto, A., Ohmori, D., Nosaka, N., Yamada, K., Torii, K. \& Ohta, M. (2007). Growth phasedependent effect of clindamycin on production of exoproteins by Streptococcus pyogenes. Antimicrob Agents Chemother 51, 461-467.

Senadheera, D., Krastel, K., Mair, R., Persadmehr, A., Abranches, J., Burne, R. A. \& Cvitkovitch, D. G. (2009). Inactivation of VicK affects acid production and acid survival of Streptococcus mutans. J Bacteriol 191, 6415-6424.

Sitkiewicz, I., Green, N. M., Guo, N., Bongiovanni, A. M., Witkin, S. S. \& Musser, J. M. (2010). Adaptation of group A Streptococcus to human amniotic fluid. PLoS ONE 5, e9785.

Smoot, J. C., Barbian, K. D., Van Gompel, J. J., Smoot, L. M., Chaussee, M. S., Sylva, G. L., Sturdevant, D. E., Ricklefs, S. M., Porcella, S. F. \& other authors (2002). Genome sequence and comparative microarray analysis of serotype M18 group A Streptococcus strains associated with acute rheumatic fever outbreaks. Proc Natl Acad Sci U S A 99, 4668-4673.
Sumby, P., Porcella, S. F., Madrigal, A. G., Barbian, K. D., Virtaneva, K., Ricklefs, S. M., Sturdevant, D. E., Graham, M. R., Vuopio-Varkila, J. \& other authors (2005). Evolutionary origin and emergence of a highly successful clone of serotype M1 group A Streptococcus involved multiple horizontal gene transfer events. J Infect Dis 192, 771-782.

Tanaka, M., Hasegawa, T., Okamoto, A., Torii, K. \& Ohta, M. (2005). Effect of antibiotics on group A streptococcus exoprotein production analyzed by two-dimensional gel electrophoresis. Antimicrob Agents Chemother 49, 88-96.

Tatsuno, I., Isaka, M., Minami, M. \& Hasegawa, T. (2010). NADase as a target molecule of in vivo suppression of the toxicity in the invasive M-1 group A streptococcal isolates. BMC Microbiol 10, 144.

Treviño, J., Perez, N., Ramirez-Peña, E., Liu, Z., Shelburne, S. A., III, Musser, J. M. \& Sumby, P. (2009). CovS simultaneously activates and inhibits the CovR-mediated repression of distinct subsets of group A Streptococcus virulence factor-encoding genes. Infect Immun 77, 31413149.

Vandal, O. H., Nathan, C. F. \& Ehrt, S. (2009). Acid resistance in Mycobacterium tuberculosis. J Bacteriol 191, 4714-4721.

von Delwig, A., Bailey, E., Gibbs, D. M. \& Robinson, J. H. (2002). The route of bacterial uptake by macrophages influences the repertoire of epitopes presented to CD4 T cells. Eur J Immunol 32, 3714-3719.

Zhang, J. \& Biswas, I. (2009). A phenotypic microarray analysis of a Streptococcus mutans liaS mutant. Microbiology 155, 61-68.

Edited by: T. J. Mitchell 